\title{
Healing after Periodontal Surgery - A Review
}

\author{
Kiran Rajesh Sethiya ${ }^{1}$, Prasad V. Dhadse ${ }^{2}$ \\ 1,2 Department of Periodontics, Sharad Pawar Dental College, Datta Meghe Institute of Medical Sciences (DMIMS), \\ (Deemed to Be University), Wardha, Maharashtra, India.
}

\section{ABSTRACT}

The native periodontium includes cementum, a functionally oriented periodontal ligament, alveolar bone and gingiva. Pathologic and / or traumatic events may lead to the loss or damage of this anatomical structure and cause wound. Wound Healing (WH) remained unclear for many years with varying concepts. Studies have shown that various surgical periodontal procedures can lead to different patterns of healing. The general principles of healing, and the cellular and molecular events observed in nonoral sites, also apply to the healing processes that take place following periodontal surgery. As periodontal-regenerative procedures are time consuming and financially demanding, there is increasing interest by clinicians to learn factors that may influence the clinical outcome following periodontal reconstructive surgery in order to provide the best possible service to patients. This goal can only be achieved if biological aspects of WH and regeneration are taken into consideration. The objectives of the present article are to discuss the basic principles of periodontal regeneration, to illustrate the factors that influence this process and to provide an overview of $\mathrm{WH}$ following periodontal surgical procedures, including scaling, root planning, curettage, gingivectomy, depigmentation, flap surgery, apically repositioned flap, replaced flap, pedicle soft tissue graft, free gingival graft, connective tissue graft, guided tissue regeneration, enamel matrix derivative, ridge preservation, osseous resection, Wilckodontics and implant. But the discovery of latest techniques have contributed to our understanding of the biology of $\mathrm{WH}$. Clinical features of $\mathrm{WH}$ of dental procedures are not often discussed. The present review focuses on the monitoring of $\mathrm{WH}$ procedures and the process of understanding the biology of periodontal tissues in periodontal and implant dentistry.

\section{KEY WORDS}

Gingiva, Periodontal Surgery, Wound Healing, Dental Implant
Corresponding Author: Dr. Kiran Rajesh Sethiya, Department of Periodontics, Sharad Pawar Dental College, DMIMS (Deemed to Be University), Wardha, Maharashtra, India. E-mail:kiransethiya16@gmail.com

DOI: $10.14260 / j e m d s / 2020 / 824$

How to Cite This Article:

Sethiya KR, Dhadse PV. Healing after periodontal surgery - a review. J Evolution Med Dent Sci 2020;9(49):3753-3759, DOI: $10.14260 /$ jemds $/ 2020 / 824$

Submission 28-07-2020,

Peer Review 23-10-2020,

Acceptance 29-10-2020,

Published 07-12-2020.

Copyright (C) 2020 Kiran Rajesh Sethiya et al. This is an open access article distributed under Creative Commons Attribution License [Attribution 4.0 International (CC $B Y 4.0)]$ 


\section{BACKGROUND}

Monitoring of wound healing (WH) following periodontal surgery is of importance. But it is more important to know the term wound or injury which means disturbance of the anatomical function and structure in any part of body, 1 whereas healing is the body reaction to trauma in order to repair normal function and structure.

On the basis of the nature of wound, soft tissue loss and presence of infection, the wound healing is classified into three general categories: primary, secondary and third intention healing.,3 Primary intention of $\mathrm{WH}$ has following features: clean and uninfected; surgically incised; without abundant loss of tissue and cells ; and margins of wound are closed by sutures. Secondary $\mathrm{WH}$ has following features: large tissue defect which is open, sometimes infected; abundant loss of tissues and cells; and the wound is left open not closed by sutures. ${ }^{4}$ Moreover, tertiary intention occurs when there is considerable loss of tissue, healing occurs by contraction of wound edges and Granulation Tissue (GT) formation. Sometimes, the presence of infection or foreign body are suspected, and these wounds intentionally are kept open for days till the probable complication is solved. When resolution occurs, the wound margins are approximated and proceeds to heal. A fourth type of WH occurs when overlying tissue is partially lost or purposely removed, so a deepithelialized Connective Tissue (CT) layer is open. It is healed by re-epithelialization from adjoining epithelium. ${ }^{3}$

\section{Outcomes of Periodontal Wound Healing 5}

Regeneration, repair and new attachment are the aspects of healing that have a special bearing on the outcome of periodontal treatment.

- Regeneration: It is biological process by which the function and architecture of lost tissues restored completely by formation of new cementum, periodontal ligament and alveolar bone.

- Repair: It is healing of tissues in which the lost tissues are not completely restored.

- New Attachment: Reunion of CT with the surface of root that is exposed pathologically.

- Reattachment: Reunion of CT and surface of root that is separated by injury or incision.

\section{FACTORS THAT AFFECT HEALING ${ }^{6}$}

\section{Local Factors}

Healing after gingival and periodontal surgery can be delayed and altered by numerous local factors. Some of these factors include -

- Plaque microorganisms.

- Extreme tissue manipulation throughout surgery.

- Damage to tissues.

- Presence of foreign bodies.

- $\quad$ Repeated surgical treatment may break cellular activity during the healing.

- Inappropriate vascular perfusion to the surrounding area.

\section{Systemic Factors}

- Age.

- Nutrition.

- Glucocorticoids.

- Un-controlled diabetics.

- Haematological abnormalities.

\section{PHASES OF WOUND HEALING}

The process has been split into 3 phases -

- Inflammation phase.

- Granulation phase.

- Matrix formation and remodelling (maturation) phase. ${ }^{7}$

\section{Inflammatory Phase}

- The GF (Growth Factor) present in clot recruit inflammatory cells, and then regulate the granulation process. In few hours, inflammatory cells colonize the clot. These helps to clean bacterial wound and necrotic tissue via phagocytosis. It also releases enzyme and toxic oxygen products. In 3 days period, inflammatory reaction moves into late phase. Macrophages emigrate the area of wound and helps in cleaning with the help of PMN (Poly-MorphoNuclear) leukocytes and erythrocytes via phagocytosis. Macrophages also releases inflammatory cytokines and tissue GF which restore inflammatory cells, endothelial cells and fibroblasts, thus play a role in transformation of inflammatory into the granulation tissue formation phase.

\section{Granulation Phase}

- The neutrophil population is overtaken by macrophages within a few days. Macrophages also serve the purpose of wound decontamination. They play key role in GT formation. It starts fourth day approximately. Macrophages constitutively releases GF that promote the process of healing. GF and cytokines secreted by macrophages are involved in proliferation and migration of endothelial cells, smooth muscle cells and fibroblasts in the area of wound. Cells extending near the radius of wound site developing cellto-cell and cell-to-matrix connections. Macrophages and fibroblasts releases GF that regulate the process of healing in an exocrine and autocrine manner. Studies have shown that wound sites supplemented with growth factors have an accelerated rate of granulation tissue formation.8,9 At 7 days, initiation of $\mathrm{WH}$, granulation dominates the wound site and the initial collagen fibres are being formed. Ultimately, cells and matrix form cell-to-cell and cell-to-matrix links that produces a concerted tension results in contraction of tissue. Formation of GT slowly progresses into the final phase of healing which alters, more cell-rich tissue undergoing maturation and remodelling to reach functional needs.

\section{Maturation Phase}

- Fibroblasts responsible for renewal of ECM (ExtraCellular Matrix) yield a new collagen-rich matrix. 1 week after wounding and collagen matrix synthesizes, few fibroblasts are converted into myofibroblasts and exhibit $\alpha$-smooth 
muscle actin. Due to conversion and synthesis there is contraction of wound. Endothelial cells cause angiogenesis which transfer into wound matrix forming vascular loops and tubes. As matrix matures, endothelial cells undergo apoptosis leading to reduction in number of vascular units. GT maturation causes regeneration or repair of the injured tissues.

\begin{tabular}{|cc|}
\hline Tissue Type & Healing Rate (Approximately) \\
\hline Junctional Epithelium & 5 days \\
Sulcular Epithelium & $7-10$ days \\
Gingival Surface Epithelium & $10-14$ days \\
Connective Tissue & $21-28$ days \\
Alveolar Bone & $\mathbf{4}-\mathbf{6}$ Weeks \\
\hline Healing Rates of Various Periodontal Tissues & $\mathbf{1 0}$ \\
\hline
\end{tabular}

\section{Clinical Requirements for Effective Healing after Periodontal Surgery}

- The application of initial therapy prior to surgical intervention

- The selection of surgical approach specific for the cure of the particular inflammatory lesion

- The type of tissue environment that exists after surgery

- The degree of fibrosis of gingiva prior to and after surgery

- Method by which the surgical wound is protected in the postoperative period

- The maintenance of the dentition and the periodontium by the patient and the dentist daily and in periodic visits

\section{HEALING AFTER VARIOUS PERIODONTAL PROCEDURES}

\section{Healing Following Scaling11}

- Day 0: Bleed and exudation of GCF (Gingival Crevicular Fluid) will remove irritants

- Epithelial attachment is severed, acute inflammatory reaction in C.T

- Day 1: After an initial lag of 12 - 24 hrs, epithelium migration begins

- Day 2: Inflammation reduces, epithelialization is enhanced.

- Day 5 : New epithelial attachment begins

- 1 - 2 weeks: Residual rete pegs involute and clinically gingiva appears healthy.

\section{Healing Following Root Planning}

- In 2 hours: Numerous PMN leucocytes seen between crevicular surface and residual epithelial cells

- There is dilation of blood vessels, oedema \& necrosis of the pocket wall.

- After 24 hrs: infiltration of inflammatory cells and keratinocytes migration seen.

- In 2 days: epithelialisation of entire pocket is seen.

- In 4 - 5 days at bottom of sulcus a new epithelial attachment appears.

- In 1 - 2 weeks depending on the depth of gingival crevice and severity of inflammation, complete epithelial healing is seen.

- Within 3 weeks CT repair by immature collagen fibres occur.

\section{Healing Following Curettage ${ }^{11}$}

- Immediately blood clot is seen in gingival sulcus which does not have epithelial lining.

- Large number of PMNs occupy site of wound after which there is rapid GT proliferation.

- Epithelium: Healing of sulcular epithelium takes 2 - 7 days and JE (Junctional Epithelium) 5 days.

- Connective tissue: Within 3 weeks immature collagen fibres appears.

\section{Healing Following Surgical Gingivectomy ${ }^{12}$}

- 2nd day

- Formation of clot

- 4th day

- Replacement of clot by GT (Granulation Tissue)

- A part of epithelial surface extends without rete pegs

- There is dense inflammatory infiltration

- 6th day

- Stratified squamous epithelium covers the wound

- In CT, formation of collagen starts

- 16th day

- Epithelium with rete pegs and dense collagenous CT occurs

- 21st day

- Well developed epithelial rete pegs and stratum corneum is thickened

- In CT, increased formation of collagen and clinically normal gingiva appears

\section{Healing Following Surgical Depigmentation}

- Immediately: clot formation takes place and acute inflammation of the underlying tissues.

- Replacement of clot by GT

- Capillaries of the PDL (Periodontal Ligament) migrate into GT

- Within 2 weeks, capillaries connect with gingival vessels.

- As healing takes place, initially vascularity increases then gradually decreases.

- Surface epithelialization is complete by 5 - 14 days.

- In 3 - 4 weeks: Complete epithelial repair takes place.

\section{Healing Following Flap Surgery ${ }^{13}$}

- Within 24 hours after suturing, contact is established by blood clot into the flap and tooth or bone surface. There is tissue injury as a result of bacteria and an exudate or transudate.

- One to three days following flap surgery - there is thin gap between flap and tooth or bone. During the close adaptation between flap and alveolar process epithelial cells move over the borders of flap and there is only a minimal inflammatory response.

- 1 week following surgery-an epithelial attachment to the root has been established with the help of basal lamina and hemidesmosomes.

- 2 weeks following surgery-collagen fibres appear parallel to tooth surface. Clinically it appears normal but the union of flap and tooth is still weak.

- 1 month following flap surgery-a well-defined epithelial attachment with fully-epithelialized gingival crevice is 
present. Supracrestal fibres begin to adapt a functional arrangement.

\section{Healing Following Apically Repositioned Flap 14}

- 1 week: There is transient acute inflammation with reorganisation of the blood clot between the tooth and flap into GT.

- 2 - 5 weeks: There is replacement of GT by CT.

- Approximately 4 weeks: epithelial migration commences from the margin of the flap and gives rise to new junctional epithelium.

- There is some resorption of the alveolar bone margin resulting from raising a flap. This is minimised by a careful surgical technique.

- Gingival margin shifts $1 \mathrm{~mm}$ coronally with long term period.

\section{Replaced Flap (Modified Widman Flap or Modified Flap) ${ }^{14}$}

- There is transient acute inflammation with reorganisation of the blood clot between the tooth and flap into granulation tissue ( 1 week) which is replaced by connective tissue $(2-5$ weeks).

- The epithelial migration commences from the margin of the flap and gives rise to new long junctional epithelium.

- This occurs over several weeks and is easily disrupted by premature probing.

- Pocket reduction is achieved by long junctional epithelial attachment to cleaned root surface.

- With long term, gingival margin may shift coronally by about $1 \mathrm{~mm}$.

\section{Healing of Pedicle Soft Tissue Grafts}

- Adaptation stage (from 0 to 4 days)

- Thin fibrin layer separates the flap from exposed surface of root. The epithelium covering the transplanted tissue flap starts to proliferate and reaches the tooth surface at the coronal edge of the flap after a few days.

- Proliferation stage (from 4 to 21 days)

- Fibrin layer present between flap and surface of root is invaded by CT proliferating from the flap subsurface. In contrast to areas where healing occurs between two CT surfaces, growth of CT into fibrin layer take place from one surface. 6 - 10 days later, fibroblasts layer is seen in opposition to the surface of root. At later stage of healing these cells differentiate into cementoblasts. In the end of this stage, formation of thin collagen fibres adjoining to the surface of root, but a fibrous union is not seen between the CT and root.

- Attachment stage (from 27 to 28 days)

- During this stage of healing, thin collagen fibres insert into newly formed layer of cementum.

- Maturation stage

- This last stage of healing is characterized by continuous formation of collagen fibres. After $2-3$ months, collagen fibre bundle insert within cementum layer on the curetted surface of root.
Healing of Free Gingival Graft ${ }^{15}$

- Initial phase (from 0 to 3 days)

- During these first days of healing, between the graft and recipient bed there is presence of exudate.

- In this period, tissue grafted will survive with an avascular "plasmatic circulation".

- For survival of graft, it is essential to establish close adaptation with the underlying recipient. Presence of blood clot or thick layer of exudate may disrupt the "plasmatic circulation" and leads to failure of graft.

- In initial phase, epithelium of the free graft degenerates early.

- Revascularization phase (from 2 to 11 days)

- 4- 5 days later, anastomoses begin into the blood vessels of grafted tissue and recipient bed.

- Thus, the blood circulation is rebuilt in the previous blood vessels of graft.

- Capillaries proliferate in the graft.

- Simultaneously, a fibrous union begins within CT bed and graft.

- Re-epithelialization of graft appears by epithelium proliferation from surrounding tissues. ${ }^{16}$

- Tissue maturation phase (from 11 to 42 days)

- In this phase, number of blood vessels in transplant is gradually decrease, and 14 days later the graft appears normal.

- During this stage there is formation of keratin layer and epithelium matures.

\section{Healing of the Connective Tissue Graft ${ }^{17}$}

- During 1st day: CT becomes disorganized and oedematous and experiences lysis and degeneration.

- As healing takes place, degenerated CT is replaced by new GT.

- By 2nd and 3rd day: revascularization of the graft starts.

- Recipient bed capillaries proliferate into graft to form new capillaries and anastomose with pre-existing vessels.

- By $10^{\text {th }}$ day, central portion vascularizes.

- 4th day: a thin layer of new epithelium is formed

- 7th day: rete pegs are developed

- By 10th day: vascular plexus get formed in graft directly below epithelium

- As seen microscopically, healing of intermediate thickness graft $(0.75 \mathrm{~mm})$ is completed by 10.5 weeks; thicker graft $(1.75 \mathrm{~mm})$ is completed by 16 weeks or longer. ${ }^{18}$

- On gross appearance, at transplantation, the graft vessels are empty and the graft is pale. In first 2 days, the pallor changes to an ischemic greyish white, until vascularization begins, and a pink colour appears.

- By 17th day: functional integration of graft occurs.

- After 1 month: graft eventually blends with adjacent tissues.

\section{Healing Following Guided Tissue Regeneration (GTR)}

Studies from histologic findings shows periodontal regeneration and Melcher's concepts of "compartmentalization" revealed a new CT attachment will occur if cells from PDL reside on surface of root during healing. ${ }^{19}$ Hence, the applications of GTR involves placing of a 
barrier membrane enabling tooth root surface to reproduce with the cells from PDL, cells from lamina propria of the gingival corium, cementum cells, and alveolar bone. GTR techniques utilize barrier membranes to facilitate the migration of bone cells and PDL cells to the defects by refraining soft tissue cells from penetrating it.

\section{Healing Following Enamel Matrix Derivative (EMD)}

Studies have aimed to characterize the early wound healing abilities of EMD in a clinical setting. Lafzi et $\mathrm{al}^{20}$ in their quantitative study illustrated that the ultrastructural changes in gingival WH after using EMD as an adjunct to a laterally positioned flap in the subjects with gingival recession. 10 days following surgery, a biopsy specimen from gingiva was obtained and examined. A considerable difference was found in both groups. In EMD group, fibroblasts were rounded with plump cytoplasm, euchromatic nuclei with well-developed rough endoplasmic reticulum and abundant mitochondria whereas in non-EMD group, fibroblasts were flattened spindle like morphology. The authors concluded that EMD may improve gingival WH features due to its antibacterial, anti-inflammatory, or anti-apoptotic properties.

\section{Healing Following Ridge Preservation 21}

- Immediately after tooth extraction blood clot is formed that fills entire socket.

- Within 48 - 72 hrs. breakdown of clot starts and infiltration of GT begins from the base of socket

- By 4 days proliferation of epithelium starts and CT starts to become apparent

- After 7 days GT gets infiltrated and replaces the blood clot

- Osteiod becomes more visible at the base of socket

- After 3 - 4 weeks entire mineralization occurs from the base of socket accomplished by the continuous reepithelization which covers the socket completely.

- 6 weeks following removal of tooth bone infiltration takes place with maximum bone density at 100 days

\section{Healing Following Osseous Resection 22}

- There is temporary loss of nutrient supply to the bone due to elevation of mucoperiosteal flap.

- In addition, surgical resection of bone takes place initially which contributes to necrosis of the alveolar crest \& osteoclastic resorption

- There is bone height loss initially which is to some extend compensated by osteoblastic repair and remodelling.

- The final bone height loss is clinically insignificant.

- Even after 1 year osteoblastic activity is seen.

\section{Healing Following Wilckodontics}

Regional Acceleratory Phenomenon (RAP) is a local reaction to tissues by noxious stimuli which regenerates tissue rapidly than normal process. The magnitude of stimulus decides the size, intensity and duration of reaction. The duration of RAP depends on type of tissue, and lasts for about 4 months in bone. This leads to healing of bone 10 - 50 times faster than normal bone. ${ }^{23}$ In human long bones, RAP begins within few days following surgery and peaks at $1-2$ months and may take 6 to 24 months to cease completely. The important principle of corticotomy procedure is that it decorticates the bone which results in transient osteopenia resulting in temporary decrease in the mineral content. The osteogenic cells start laying down abundant deposits of calcium followed by bone mineralization within a period of about 20 - 55 days. During this transient state, orthodontic brackets help in moving the teeth more rapidly because the immature bone offers decreased resistance to the orthodontic forces. After the complete recovery procedure, in every 2 weeks orthodontist adjusts the braces depending on case. A retainer for at least 6 months is recommended after the braces are removed.

\section{Healing Following Implant Placement 24}

- Immediately, blood clot occurs in the implant mucosa interface.

- In 4 days, abundant neutrophils infiltrate the blood clot and an initial mucosal seal is formed.

- The area with PMNs reduces and confines to the coronal portion, but collagen and fibroblasts dominate the apical part of implant-tissue interface.

- Peri-implant JE is $0.5 \mathrm{~mm}$ apical to the mucosal margin in 1 - 2 weeks.

- Peri-implant JE started to proliferate in the apical direction in 2 weeks.

- Peri-implant mucosa is rich in blood vessels and cells after 2 weeks.

- Peri-implant JE migrates apically and occupies $40 \%$ of entire soft tissue implant interface at 4 weeks. The soft CT is rich in fibroblasts and collagen. It is well-organized.

- In 6 - 8 weeks: complete migration peri-implant JE apically and a dense layer of fibroblasts on titanium surface.

- From 6 - 12 weeks: soft CT matures and peri-implant JE occupies $60 \%$ of total implant soft tissue interface.

\section{Healing in Immediate Implant Placed in Fresh Extraction Socket}

Vignoletti et al. ${ }^{25}$ in their histologically and histomorphometrically study described the early phases of soft tissue WH around implants placed into fresh extraction sockets in dogs. Authors noted that within $1^{\text {st }}$ week of healing there is fast down growth of peri-implant JE apically. At 8 weeks a final biologic width of approx. $5 \mathrm{~mm}$ with a peri implant JE measuring $3.0-3.5 \mathrm{~mm}$. Alike results were described by Rimondini et al. ${ }^{26}$ in minipigs and by de Sanctis et al. ${ }^{27}$ around different implant systems in dogs. Previous per implant soft tissue dimensions varies from the other studies in which implants were placed into fresh extraction sockets in dogs. ${ }^{28}$ Thus it was concluded that when implants are placed into fresh extraction sockets there was faster apical migration of the peri-implant JE and formation of a greater final biologic width dimension, particularly like the epithelial component. 


\section{CONCLUSIONS}

In pathology, wound healimg refers to healing of injured tissue by living tissue. A deep perception of clinical and biological variables affects the periodontal regeneration and allows the dental practitioner to redirect clinical and biological factors effectively to enhance clinical result and increase periodontal regeneration.

Healing is ideal when there is acceptable aesthetics and appropriate function. Therefore, a meticulous knowledge regarding the relationship and nature of various periodontal tissues is needed to attain satisfactory healing which result in the development of new periodontal ligament, alveolar bone and cementum, and properly secured by gingival tissue.

Financial or other competing interests: None.

Disclosure forms provided by the authors are available with the full text of this article at jemds.com.

The authors acknowledge the scholars whose articles are cited and included in references of this manuscript. The authors are also grateful to authors / editors / publishers of all those articles, journals and books from where the literature for this article has been reviewed and discussed.

\section{REFERENCES}

[1] Robson MC, Steed DL, Franz MG. Wound healing: biologic features and approaches to maximize healing trajectories. Curr Probl Surg 2001;38(2):72-140.

[2] Messadi DV, Bertolami CN. General principles of healing pertinent to the periodontal problem. Dent Clin North Am 1991;35(3):443-57.

[3] Hupp JR. Wound repair. In: Peterson LJ, Ellis E, Hupp JR, et al, eds. Contemporary oral and maxillofacial surgery. $4^{\text {th }}$ edn. St. Louis: Mosby, Inc 2003.

[4] Polimeni G, Xiropaidis AV, Wikesjo UM. Biology and principles of periodontal wound healing / regeneration. Periodontol 2000 2006;41(1):30-47.

[5] Reddy S. Rationale for Periodontal Treatment. In: Reddy $S$, ed. Essentials of clinical periodontology and periodontics. $3^{\text {rd }}$ edn. New Delhi: Jaypee Brothers Medical Publishers (P) Ltd 2011: p. 269.

[6] Guo SA, DiPietro LA. Factors affecting wound healing. J Dent Res 2010;89(3):219-29.

[7] Wikesjo UM, Nilveus RE, Selvig KA. Significance of early healing events on periodontal repair: a review. J Periodontol 1992;63(3):158-65.

[8] Sporn MB, Roberts AB, Shull JH, et al. Polypeptide transforming growth factors isolated from bovine sources and used for wound healing in vivo. Science 1983;219(4590):1329-31.

[9] Giri RR, Giri KR, Patel SS, et al. Effect of Terminalia arjuna in accelerating healing process of experimentally fractured tibia of rats: a preliminary study. Research Journal of Pharmaceutical, Biological and Chemical Science 2012:3(4):417-25.

[10] Bathla S. General principles of periodontal surgery. In: Bathla S, ed. Periodontics Revisited. $1^{\text {st }}$ edn. New Delhi: Jaypee Brothers Medical Publishers (P) Ltd 2011. p. 340.
[11] Carranza FA, Takei HH. Gingival curettage. In: Newman MG, Takei HH, Carranza FA, eds. Carranza's clinical periodontology. $9^{\text {th }}$ edn. W.B Saunders Company 2002.

[12] Novaes AB, Kon S, Ruben MP, et al. Visualization of the microvascularization of the healing periodontal wound. 3. Gengivectomy. J Periodontol 1969;40(6):359-71.

[13] Kon S, Novaes AB, Ruben MP, et al. Visualization of the microvascularization of the healing periodontal wound. IV. Mucogingival surgery: full thickness flap. J Periodontol 1969;40(8):441-56.

[14] Clerehugh V, Tugnait A, Genco R. Types of periodontal surgery. In: Clerehugh V, Tugnait A, eds. Periodontology at a Glance. $1^{\text {st }}$ edn. Oxford, UK: A John Wiley \& Sons Ltd 2009: p. 51.

[15] Gargiulo AW, Arrocha R. Histo-clinical evaluation of free gingival grafts. Periodontics 1967;5(6):285-91.

[16] Gupta VK, Pathak SS. Screening of burn wound healing property of ocimum sanctum by grading of epithelial regeneration in rabbits. Research Journal of Pharmaceutical, Biological and Chemical Sciences 2016;7(3):538-42.

[17] Del Pizzo M, Modica F, Bethaz N, et al. The connective tissue graft: a comparative clinical evaluation of wound healing at the palatal donor site. A preliminary study. J Clin Periodontol 2002;29(9):848-54.

[18] Gordon HP, Sullivan HC, Atkins JH. Free autogenous gingival grafts. II. Supplemental findings--histology of the graft site. Periodontics 1968;6(3):130-3.

[19] Melcher AH. On the repair potential of periodontal tissues. J Periodontol 1976;47(5):256-60.

[20] Lafzi A, Farahani RM, Tubbs RS, et al. Enamel matrix derivative emdogain as an adjuvant for a laterallypositioned flap in the treatment of gingival recession: an electron microscopic appraisal. Folia Morphol (Warsz) 2007;66(2):100-3.

[21] Amler MH, Johnson PL, Salman I. Histological and histochemical investigation of human alveolar socket healing in undisturbed extraction wounds. J Am Dental Assoc 1960;61(1):32-44.

[22] Nyman S, Rosling B, Lindhe J. Effect of professional tooth cleaning on healing after periodontal surgery. J Clin Periodontol 1975;2(2):80-6.

[23] Schilling T, Müller M, Minne HW, et al. Influence of inflammation-mediated osteopenia on the regional acceleratory phenomenon and the systemic acceleratory phenomenon during healing of a bone defect in the rat. Calcif Tissue Int 1998;63(2):160-6.

[24] Sculean A, Gruber R, Bosshardt DD. Soft tissue wound healing around teeth and dental implants. J Clin Periodontol 2014;41(Suppl 15):S6-22.

[25] Vignoletti F, Johansson C, Albrektsson T, et al. Early healing of implants placed into fresh extraction sockets: an experimental study in the beagle dog. De novo bone formation. J Clin Periodontol 2009;36(3):265-77.

[26] Rimondini L, Bruschi GB, Scipioni A, et al. Tissue healing in implants immediately placed into postextraction sockets: a pilot study in a mini-pig model. Oral Surg Oral Med Oral Pathol Oral Radiol Endodontol 2005;100(3):e43-50.

[27] Vignoletti F, De Sanctis M, Berglundh T, et al. Early healing of implants placed into fresh extraction sockets: an experimental study in the beagle dog. III: soft tissue findings. J Clin Periodontol 2009;36(12):1059-66. 
[28] Araújo MG, Sukekava F, Wennström JL, et al. Ridge alterations following implant placement in fresh extraction sockets: an experimental study in the dog. J Clin Periodontol 2005;32(6):645-52. 